\title{
The shaping process of urban form under a socialist system: Townscape diversity and its formation in Sanlitun, Beijing
}

\author{
Yang Meng, Miao Zeng, Feng Song* \\ College of Urban and Environmental Sciences. Peking University. Beijing. China \\ *(corresponding author) \\ E-mail: 108158186@qq.com, charlinez@163.com,songfeng@urban.pku.edu.cn
}

\begin{abstract}
The difference between socio-economic systems is an important factor in the diversity of urban form. M. R. G. Conzen (1960) established a framework for urban morphology in the context of a British social system and culture. It was suggested that this did not necessarily apply to cities affected by revolutionary planning measures. China, which is markedly different in social system and culture from Britain by most standards qualifies as revolutionary, at least in the post-war period. Sanlitun in Beijing, China, is an interesting case for comparison with British cities. It was a site containing few buildings during the initial stage of new China, but subsequently became the 'Second Embassy District' where many embassies gathered. Now it has become a commercial core district and cultural meeting place of Westerners and Chinese. The townscape of Sanlitun, which has experienced a number of socialist construction periods reveals the process of changing urban form under a socialist system. Identifying morphological periods, the changing process of townscape development in Sanlitun is articulated. Morphological units are delimited. They clarify the variations in Sanlitun's landscapes and their formation. Based on these, this paper reflects on the shaping process of townscape under different socio-cultural systems, and further considers the universality, applicability and particularities of Conzenian theory.
\end{abstract}

Keywords: socialist system, townscape, urban form, M. R. G. Conzen

\section{Related Background}

To discuss this issue, we choose the Sanlitun area of Beijing as our case. Sanlitun has experienced different periods of socialist construction and has retained a relatively complete space remain, which can show us the evolution of urban form under the socialist system.

Before discussion, we should clarify 'Socialist System', 'shaping process' and the reason to choose Sanlitun as the case. The present social system can be divided into the socialist system and the capitalist system speaking in general. Unlike the Cuban, North Korea or the former Soviet Union, China's socialist system had experienced a more tortuous development, and ultimately formed the socialist system with its own unique characteristics, which is different from others. The comparison of urban form in different social systems will help us to explore more general theories about the interpretation of urban landscapes under different systems. On the other hand, the shaping process of urban form refers to the operation and transformation of urban space. We call it socialist practice, or practice of socialism, which means all the activities that human beings can transform nature and society with purpose and initiative. Under the socialist system, the operation and practice of space can be divided into two kinds: one is built or reconstructed on the original urban landscape, the other is built on a blank 
space. The difference between the two kinds lies in the evolutionary of the construction and development of urban landscape. On the basis of the original urban landscape which is not completely removed, either building or rebuilding will retain the characteristics of urban landscape during the last stage. But the spatial practice on the basis of the blank and no urban landscape will reflect the influence of the social system in the specific historical period to the greatest extent, and the typical representative is Sanlitun. In the early days of the founding of the people's Republic of China, Sanlitun did not have large-scale urban development and retained a relatively complete agricultural landscape. It was a "blank land" and was suitable for the study.

In conclusion, Sanlitun area of Beijing, which has been called "the trend vane", "bar street", and "the cradle of Beijing night life" has the following advantages as a case study. The first reason is experience simplicity. There is no urban construction before the founding of the People 's Republic of China, so the study of changing process of urban form in Sanlitun can reflect the social practice under the socialist system characteristics better. The second reason is experience particularity. Sanlitun is the place where Second embassy districts stand and it is the birthplace for original source of western culture. The last one is experience integrity. Sanlitun has experienced different periods of socialist construction and has retained a clear physical space remains, which is an excellent case to explore the townscape evolution and social changes.

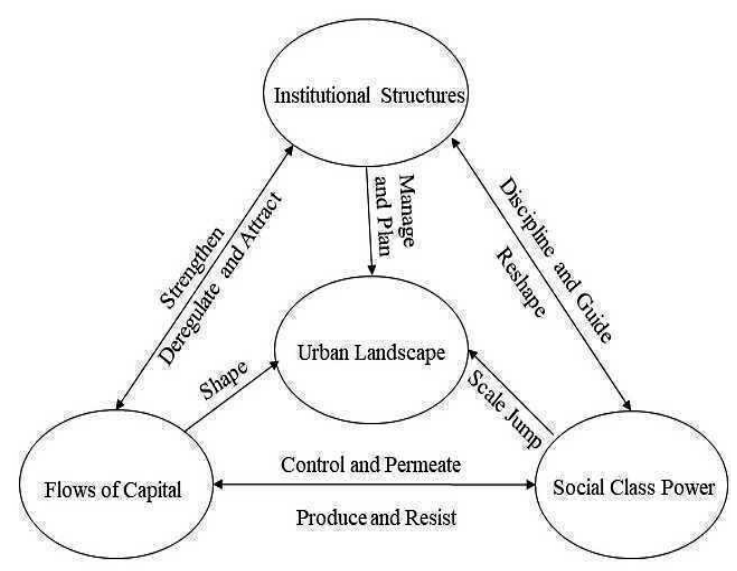

Figure 1.
After analysis of urban form, we use the theory production of space to interpret the dynamic mechanism of the townscape evolvement. To clarify the spatial practice under the socialist system, we must pay attention to not only the view of geography but also the view of social science system. A more appropriate interpretation theory is Harvey's improved theory of production of space, which integrates space and society together instead of the dualism of traditional space and society.

Theory production of space, put forward by French thinker Lefebvre in 1970s, has revealed the relationship between space and factors which shape it in social, political and economic fields. The theory not only has a profound impact on urban studies, but also on geography, sociology, Marx doctrine politics, economics, literature, art, architecture and other fields. Lefebvre constructed the theory production of space, which took the urban space as the product of capitalist production and consumption activities as the core viewpoint. After that, many geographers were influenced by Lefebvre's thought, and further, extended or perfected their theories. Among them were David Harvey (1973), who made a critical interpretation of the classical doctrine of Marx, and put forward the theory of "Urbanization of Capital" based on Lefebvre's thought. In the three stages of capital circulation, over accumulation of capital leads to more investment into urban environment and social service. The theory, however, confined to the social and economic spatial process of production, ignoring the role of political power and institution played in the process. In this study, the institutional structures represented by government and authorities' regulation of society should be introduced to complete the new cycle.

This study interprets the dynamic mechanism of evolution of urban landscape and adopts the theory production of space. The theory this study uses is based on Lefebvre the production of space and David Harvey's Three Stages of Capital Circulation theory. From the theory, the government and authorities' regulation of society represented by institutional structures, the reunion of social class power represented by the masses of society, and the flows and 


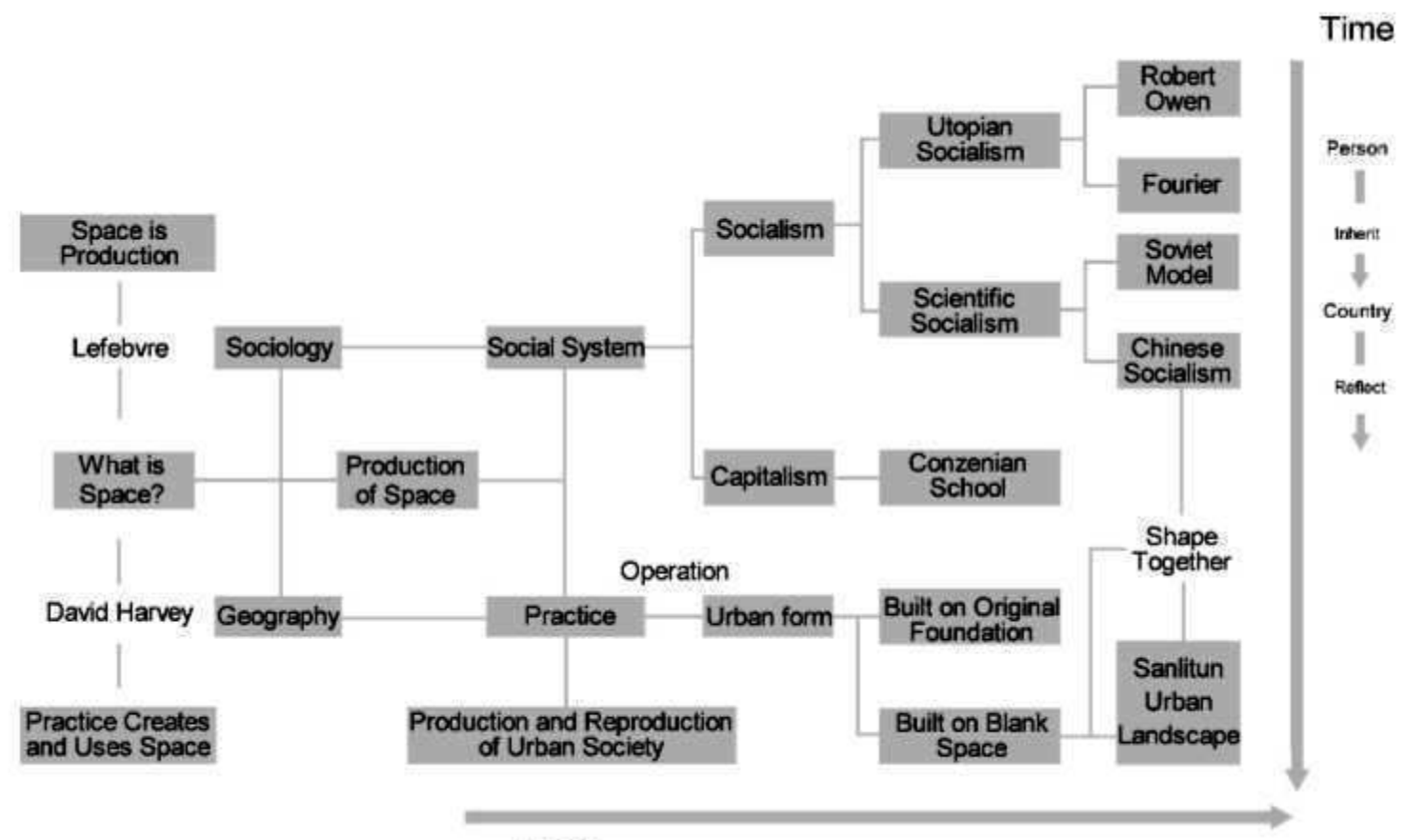

Time

Figure 2.

Pedigree diagram of research

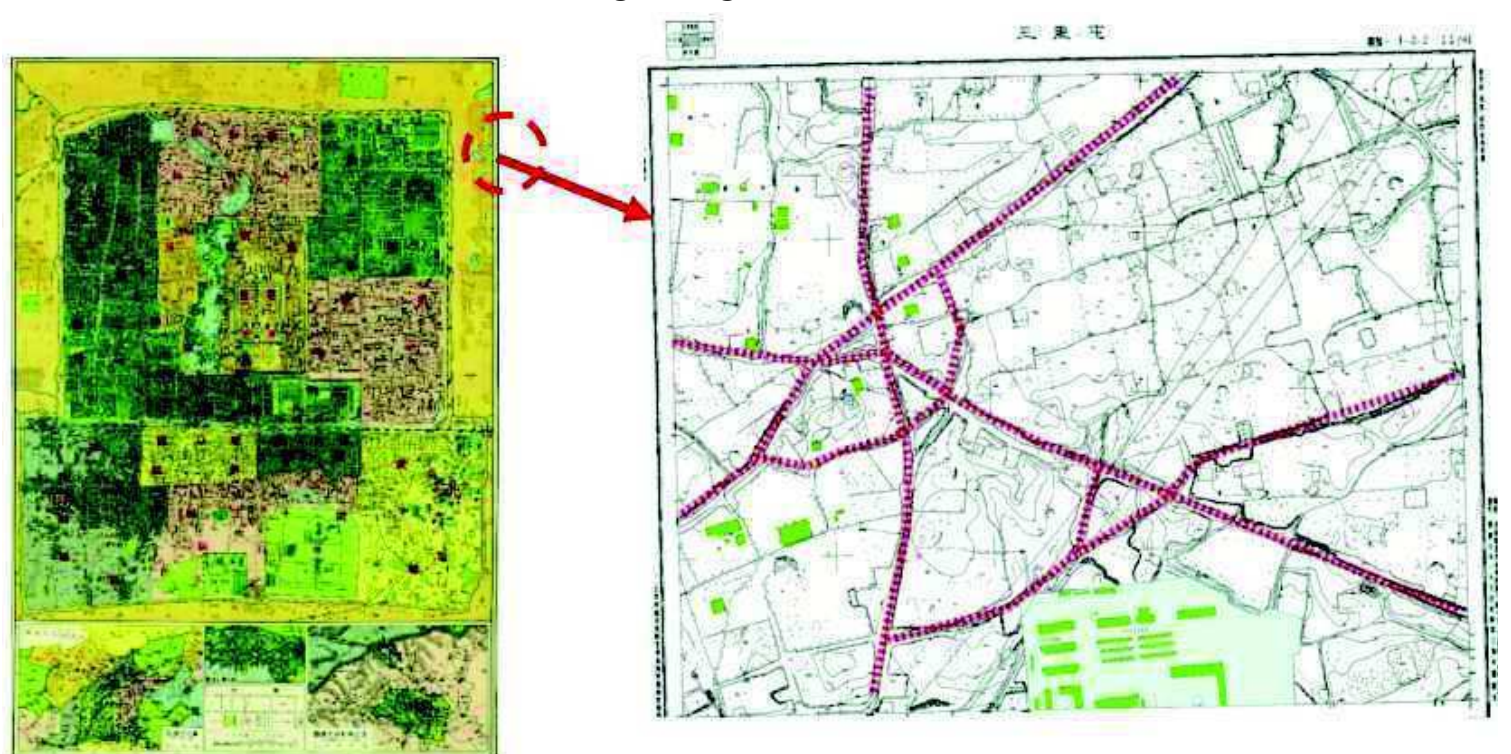

Figure 3.

Natural Form of Sanlitun in June, 1955

accumulation of capital represented by capitalists with finance corporations. The urban landscape is summed up as the interaction of the three.

\section{Location Conditions}

The location of Sanlitun determines its social and economic status in Beijing, and further determines the possible direction of its development. This paper first analyzes the regional conditions of Sanli tun from two aspects: the natural base and the social economic condition.

This map measured by Bureau of Surveying and mapping in Beijing in June, 1955 showed us a natural form of Sanlitun. The red dashed 


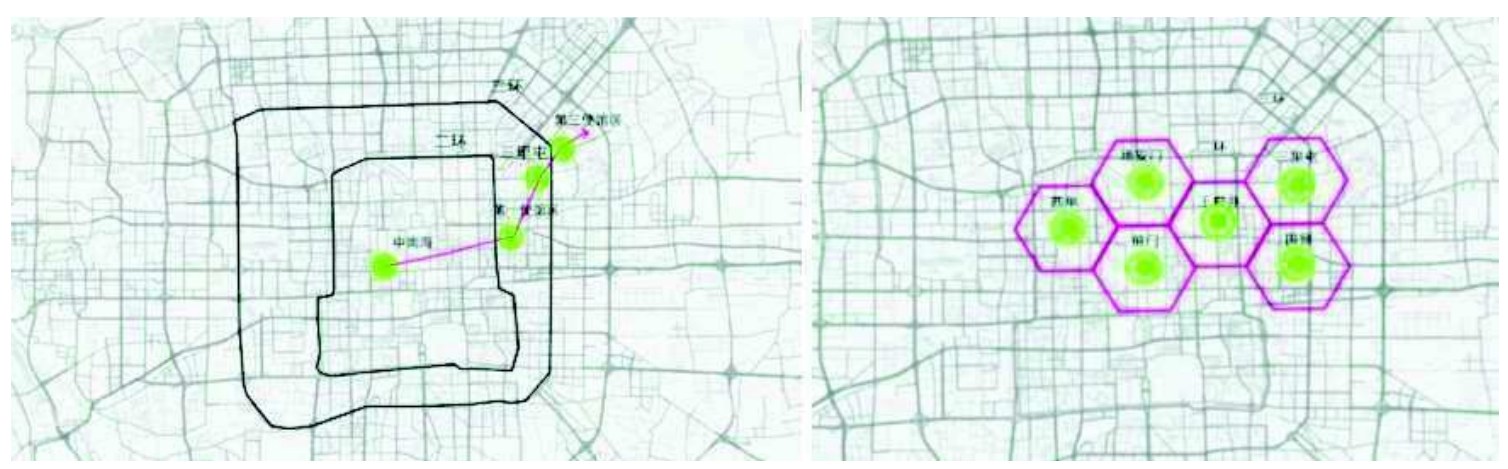

Figure 4.

Sanlitun Political Location and Economic Location.

line was used to draw up the natural ravines that were not artificially converted. The green blocks were used to mark the buildings that existed at that time. In terms of physical geography, it was a normal and insignificant farmland outside Beijing Xizhimen three miles away, but its flat and fertile land which was suitable for construction and the location close to the center of the old city gave it a development potential.

From the political point of view, the Zhongnanhai in Beijing city as the political center, formed a political influence on line relationship with Sanlitun, the first embassy district and the third embassy district. Compared with the old city center as a national political center, Sanlitun is the political power of international communication region. It is more international than the center of the city, and has more open political and cultural atmosphere.

From the impact of Sanlitun and its important economic centers nearby around the city, Sanlitun expanded outward to be the new center next to the original one of Xidan and Tiananmen Square. From the perspective of location, it had the opportunity to become the new Beijing City Service center. Later, because of the organic evacuation, the protection of the old city and the expansion of the economic center in Beijing, Sanlitun became the most important center in the economy instead of the former.

The later political and economic decisionmaking, which include location of the second embassy district and eastward move of economic center of Beijing, had a further change on its location conditions.

\section{Morphological Periods}

According to the history of macro social changes and the history of urban construction in China, the social change has experienced two tremendous turning points since the founding of China. The first turning point was 1949 in which top-down planning of urban construction prevailed in this planning economy period. The second turning point was 1978 in which commercial city development organized by economic market dominated in reform and opening up period. Combined with the history of Sanlitun, we have made a brief division of morphological periods of Beijing, which has been called (i) Pre-modern agricultural landscape period (1949 1952), (ii) Socialism initial accretion period (1952 1982), and (iii) Socialism redevelopment period (1982 now).

(i) Pre-modern agricultural landscape period (1949 1952)

During this period, China was in the early days of the founding, and had not carried out a largescale transformation plan.

Morphological frame: The morphological frame in this period was an original natural frame dominated by irrigation canal system which was the expansion of natural waterways.

Plan unit (I): River irrigation system organized two kinds of plan elements of the agricultural production: one were the numerous farmland unit, including the farmland as production and the farmhouse scattered around. The other were few sacrificial unit, which occupied a number of special locations to provide special public service for the whole community - ritual activities. 

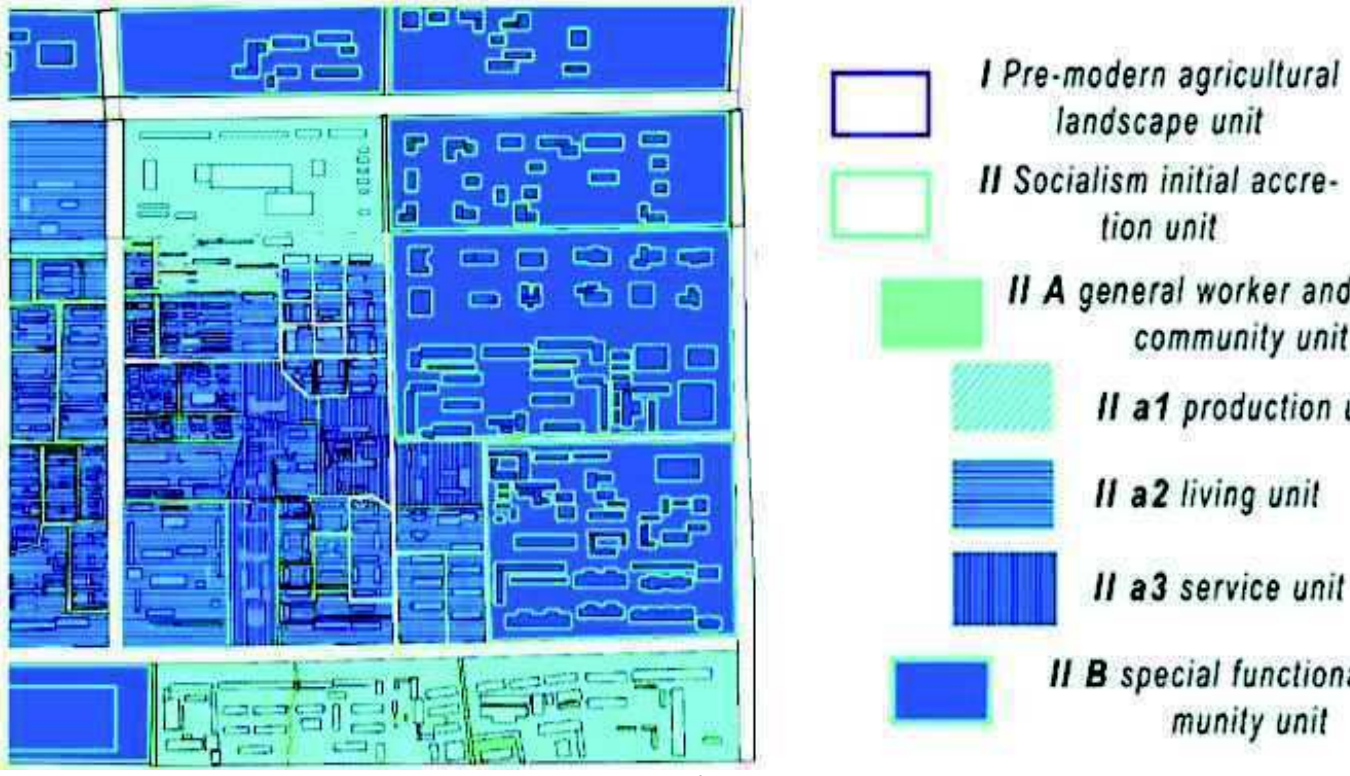

I Pre-modern agricultural landscape unit

II A general worker and peasant

community unit

II a1 production unit

II a2 living unit

II a3 service unit

II B special functional com.

munity unit

Figure 5.

Plan-units of Sanlitun during Socialism Initial Accretion Period.

Plot pattern: Farmland unit was formed by an irregularly shaped farmland and some farmhouses which were in the middle of the land. The irregular farmland mosaiced together, which was connectted by the whole system of irrigation canals. Sacrificial unit always occupied an isolated ground, such as the intersection of mountains or canal, and also had a lager building for ritual activities.

(ii) Socialism initial accretion period (1952 1982)

With the construction of the capital city, the area entered the Socialism initial accretion period. Under the new planning system, the core of the old city of Beijing stepped into the period of accretion, which reflected in new morphological frame and new plan unit.

Morphological frame: From the morphological framework, the irrigation canal, as a primitive framework, was completely wiped out and replaced by a rapidly constructed network of straight grid patterns, and the natural fixation line river was also regulated.

Plan unit (II): In order to reorganize the social life quickly and effectively, a new basic unit called "Danwei" appeared. One Danwei integrated all aspects of social production, living and public service facilities. A large and fast copy of this basic unit was the model for basic construction during this period. In Sanlitun, this unit was divided into two parts because of the difference between function and morphology: the gerenal worker and peasant community unit (II A) and the special functional community unit (II B).

The gerenal worker and peasant community unit (II A) were typical morphological unit of this period. There are three different types: a community in which the plant was used as a production unit (II a1), a community in which the workers and peasants village was used as a living unit (II a2), and a community in which affiliated schools, hospitals, and community management station were used as a service unit (II a3).

The special function unit (II B) refered to the embassy district and the corresponding police department. In fact, they could also be viewed as a unit, all of the consulate and the police unit were the "production unit", the Diplomatic Apartments were the "living unit", and corresponding Armed Police hospital and kindergarten were the "service unit". But such unit, due to the special nature of the production sector, made it distinct from the normal community.

Plot pattern: The three different unit in the gerenal worker and peasant community unit lay in a combination arrangement. They were 

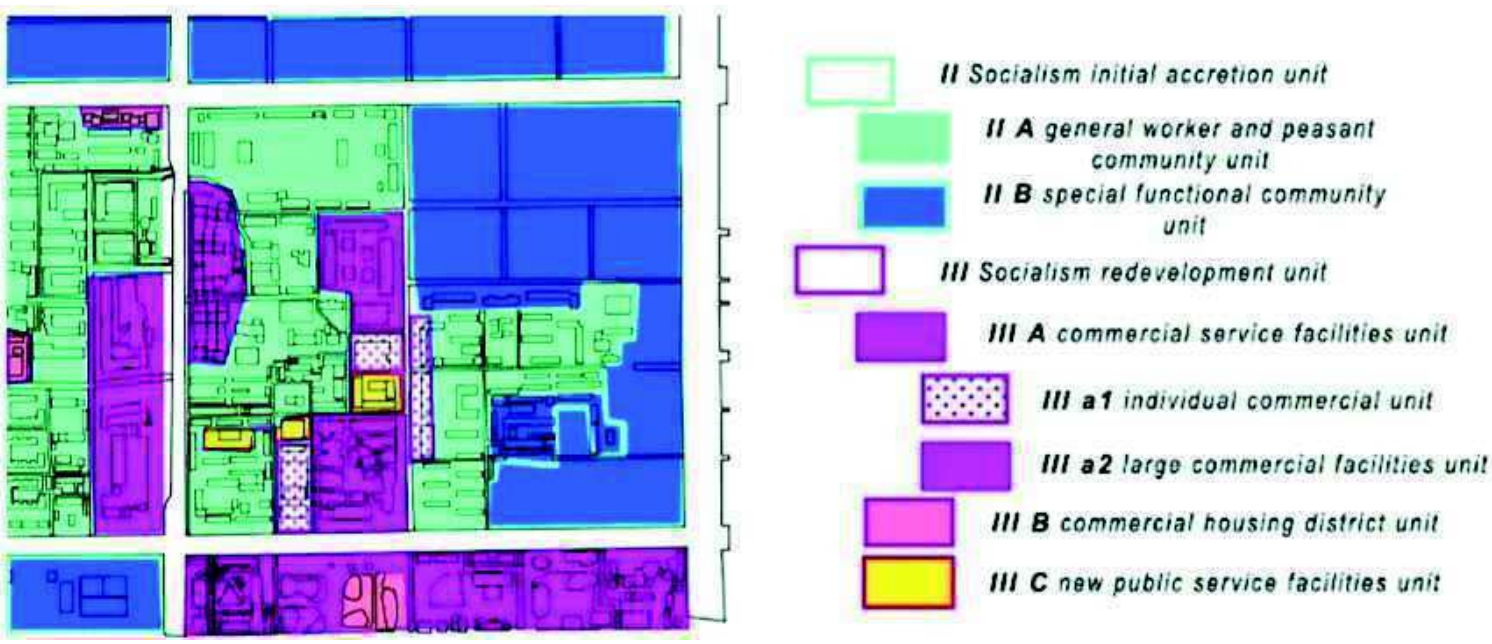

Figure 6.

Townscape -units of Sanlitun during Socialism Redevelopment Period.

close to others in space and in a higher building coverage.

The buildings in special function unit were larger, and the plot's boundary was clear and relatively close. Its concrete construction pattern is closely related to its function.

(iii) Socialism redevelopment period (1982 now)

With the transition from the planning economy period to the market economy period, the urban construction of Beijing fully responds to the market economy, Sanlitun stepped into the Socialism redevelopment period.

Morphological frame: The basic frame of the grid road system had not changed, but the left undone path of the previous period has completed the final construction.

Plan unit (III): During this period the status of the two types of unit were different. The special function unit were relatively static, and the gerenal worker and peasant community unit had emerged alienation. This alienation was mainly due to the disintegration of Danwei system, making the city's production, living and service unit no longer closely related to Danwei as a core. Every alienation unit is divorced from the original community, and has commercial characteristics in function. They entered into a larger market, and through the market organization and deployment, a commercial redevelopment would be previled. From the planned economy to the market economy, the biggest change is the organization mode of production: the original way of community organization is transformed into enterprise organization.

The alienation process of these unit could be divided by the land redivided and the land redevelopment. From the land redivided process, the unit alienation could be divided into three different types: the production unit's alienation, the living unit's alienation and the service unit's aliention. Since the industrial goal of Beijing had transformed from heavy industry to the third industry, the original factory shut down and its plot went into redevelopment of land overall. The production unit had been alienated to commercial service facilities unit (III A) and commercial housing district unit (III B). With the change of welfare housing distribution system to commercial housing system, the living unit also faced with a commercial redevelopment, which also had been alienated to commercial service facilities unit (III A) and commercial housing district unit (III B) . But the redevelopment of the community had shown the characteristics step by step. The frontage which had the highest commercial value redeveloped first, and then gradually moved to the inside of the land. The service unit's aliention was not showen at the material level, but at the level of the service, from the community dedicated service, into the urban public service system. The new service facilities were called new public service facilities unit (III C). 
From the land redevelopment process, the old production and living unit were transformed into new production and living unit, which were commercial service facilities unit (III A) and commercial housing district unit (III B). To the commercial service facilities, because of the differences between production subject and production organization mode, they could be divided into two different new unit: the individual commercial unit (III a1) and the large commercial facilities unit (III a2). The individual commercial unit (III a1) is selfemployed business gathered spontaneously from bottom to top, while the large commercial facilities unit (III a2) is large-scale commercial development led by government from top to bottom.

Plot pattern: For the plot pattern, the redevelopment for the land of commercial reflected a linear development and expansion along the street, and for the land of living reflected centrality, which formed a habitationcentric pattern where service industry expanded around.

\section{Types of Plan-unit}

From the perspective of townscape evolvement process, the geographical structure of the plot has been clearly demonstrated in front of us. Through the differences in the formation period, the townscape is divided into three major parts: the pre-modern agricultural landscape unit (I), the socialism initial accretion unit (II), and the socialism redevelopment unit (III). The premodern agricultural landscape unit (I) has not existed any more in this area.

During the socialism initial accretion period, the basic morphological frame of the plot has been established, and two types of plan-unit has formed: the gerenal worker and peasant community unit (II A) and the special functional community unit (II B). These two types take Danwei as a common ground: production, livelihood and public service can be organized as a whole in Danwei, a resident of Danwei may fulfill his all requirements in Danwei. The Danwei communities under these socialist practices form a typical urban landscape in Sanlitun: The collective production space enclosed by a high wall; the central building or administrative office as a symbol of the leadership of the Party (such as the empty political art troupe and armed police units), or Danwei community centeral in a production plant with the service facilities such as kindergartens, hospitals, activities room surronding around. The characteristics of the urban form at that time are highly integrated and low differentiation, which is related to the planned economy period. The different point is that the special functional community unit is diplomatic or military district which has a unique and significant stability. According to the differences of social function, the gerenal worker and peasant community unit (II A) can be divided into the production unit (II a1), the living unit (II a2), and the service unit (II a3).

During the socialism redevelopment period, the socialist economic system transformed from planned economy to market economy. Housing commercialization and privatization reform has weakened Danwei system gradually. The combination of production and livelihood in Danwei is gradually separated by the alienation in market economy. The living units gradually become the community system - the new commercial housing estates, which is characterized by low integration and high degree of differentiation, forming a new type of public service facilities and space. The production units alienate into commercial service facilities. Different development subjects lead to different commercial facilities with high degree of differentiation and diversified development of organizational functions.

The morphological frame has remained unchanged, and the alienation of plan unit has appeared. The special functional community unit (II B) have remained unchanged, the secondary unit of gerenal worker and peasant community unit (II A) alienate partly. The new unit called the socialism redevelopment unit (III) can be divided into three major parts: the commercial service facilities unit (III A), the commercial housing district unit (III B) and the new public service facilities unit (III C). The commercial service facilities unit (III A) can be divided into two different new secondary unit: the individual commercial unit (III a1) and the 
large commercial facilities unit (III a2).

To sum up, different morphological periods, different functions and different development patterns of plan unit are intertwined, and interact continously, reshaping the urban landscape in Sanlitun which makes it full of diversity and uniqueness. The diversity of urban landscape in Sanlitun is embodied in two existing periods - the Socialism initial accretion period and Socialism redevelopment period (II/III), and the existing plan unit between the gerenal worker and peasant community unit (II A) and special functional community unit (IIB), the existing plan unit between individual commercial unit (III a1) and large commercial facilities unit (III a2).

\section{Dynamic Mechanism}

We choose the most complex and contradictory plots (it is the interface of the gerenal worker and peasant community and embassy district, and it is the place where tha Bar street stands), Sanlitun Village and its surronding areas, as our study object.

During the two turning points, the relationship between the three actors have significant difference. During the period of the socialism initial accretion, government and authorities supervised the masses of society in the production and living space from top to bottom. In a completely unified action, the construction and production of new urban areas have been rapidly established. During the period of the socialism redevelopment, masses of society carried out redevelopment for the Bar Street spontaneously at first, which had an influence on the scale jump from region to city, even to the whole country. With the government stepping in, the original public domestic service facilities were guided and transformed into foreign service facilities. In the later period, the housing authority designated by the governmet guided owners of capital as new actors to step in. Some parts of land ownership had been transferred, and the owners of capital will rebuild community service facilities for a large commercial village. The capitalists were involved as a new actor. Under the supervision of the government, masses of society and the

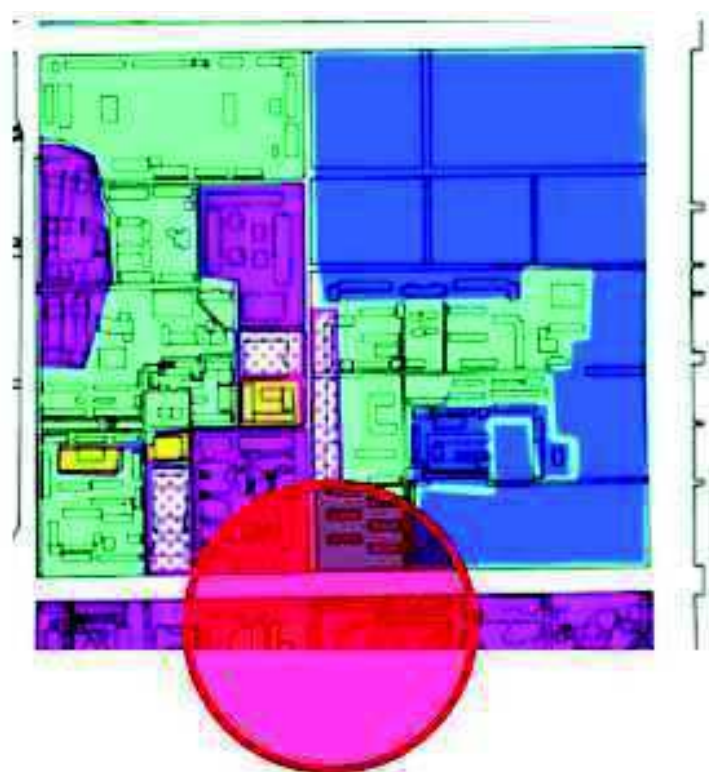

Figure 7.

Sanlitun Village- the Most Complex and Contradictory Plot

capitalists compete and cooperate with each other, and realize the commercial development of Sanlitun in the process of conflict and interaction.

In a relatively complete manner, we use the theory of "production of space" to interpret the evolution of urban landscape. It is obvious that, in the pre-modern agricultural landscape period, government and authorities took the main power of shaping urban landscape. However, the social class power took the main role in Socialism initial accretion period. Further, in Socialism redevelopment period, those three powers influence each other to shape the urban landscape: under the supervision of the government, masses of society and owners of capital both competed and cooperated with each other. The process of commercial development of Sanlitun was achieved in conflict and interaction. As a matter of fact, the nature of the dominant forces of all periods is determined by the current social system. In Pre-modern agricultural landscape period, governmental regulation leads the urban development; In Socialism initial accretion period, due to the Danwei system, the government leads masses of society to complete the development from bottom to the top; In Socialism redevelopment period, the practice entity shifted to sole proprietorship, 
bar street as a typical example, and large capital modern company. As the reforming and opening-up policy took place, and socialist economy system came into being which led to the demolishment of Danwei system and introduction of the foreign culture. Under the supervision of the government, masses of society and the capitalists compete and cooperate with each other. And that explains why those three powers could find a balance. In summary, in whatever period, the space development and practice cannot be discussed without mentioning the socialism structure.

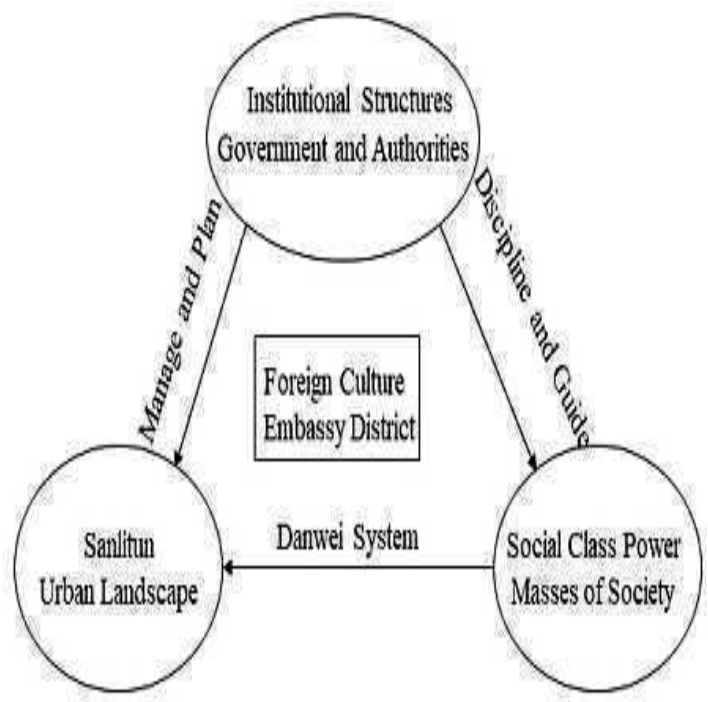

Figure 8.

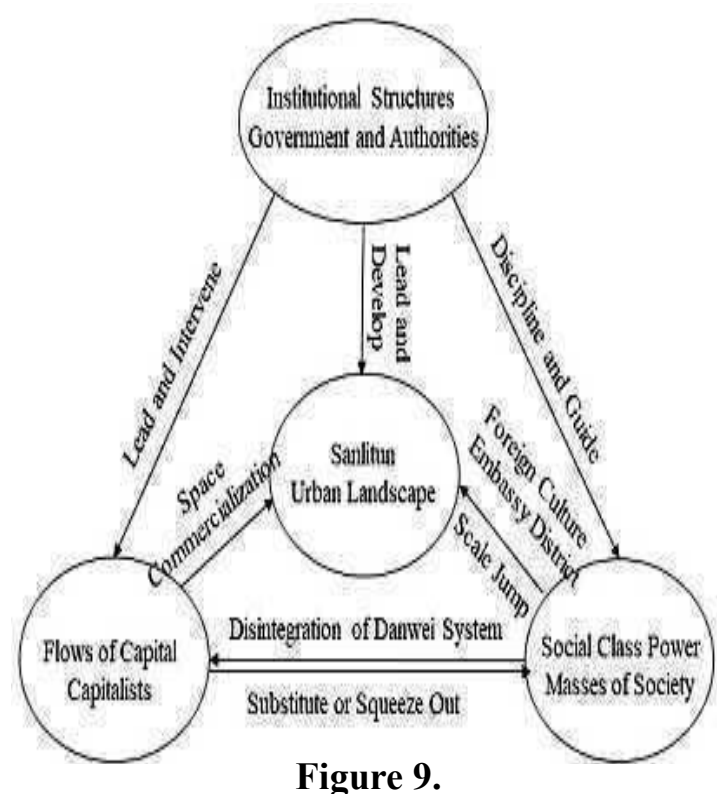

Analysis of Dynamic Mechanism of Urban Landscape during the Second Evolution.
Also, the practices of space development in different periods all have unique features. Social system determines the different leading and developing forces in different periods, thus completing the spatial practice and morphological transformation in different periods of Sanlitun.

So, in the evolution of urban landscape, the social system is always controlling the form. It controls the main power of decision and development in different periods, so that Sanlitun was reformed. As a reflection of the requirements and features of socialism system in each historical period, the changes of urban form in Sanlitun could reflect the change of social system. In a nut shell, we believe it is the evolution of the social system that pushes the development of Sanlitun in terms of urban landscape.

\section{Conclusion and Prospect}

By comparison the urban landscape of Sanlitun reflects the characteristics of the Socialist space practice as follow: the first one is institutional. The space practice in Sanlitun reflects Chinese social system deeply. From the people's commune, the system of Danwei, SOHO to the bar street, we can see different requirements of the socialist system for the different periods, so it can be said that the space practice of Sanlitun is unique to the others. The second one is delay. The spatial practice realized in Sanlitun is roughly the same as that on the national level, but lags behind in different degrees at the time level. The third one is cultural particularity. Compared with other domestic socialist practice, although in the same social system, Sanlitun still has its obvious morphological particularity: the influence of foreign culture. The concrete manifestation is the embassy district and the bar street. Magnified by the social class power, they attracted the capital in the socialist market economy and formed the present urban landscape of Sanlitun in the process of shaping urban form. Therefore, foreign culture plays an important role in the space practice of socialism in Sanlitun. Based on the above basic characteristics, the article continues to reflect on the particularity of the 
urban form under socialist system in crosscultural comparison.

The first one is fixation line and morphological frame. Fixation line is defined as a strong, protective and linear ground, such as a wall that marks the traditional, static edge of an ancient town. The field of Alnwick was recognized as the morphological frame since the middle ages. After several hundred years, its ownership and boundaries had been adjusted, but until now, there are still some reservations and remnants, which have become the boundary of plane-unit today. In Sanlitun however, the irrigation system as the framework of original agricultural landscape was rapidly and completely erased. Instead, a strict network of grid road system and a manmade river course form a new morphological frame with a history of only twenty years. The new morphological framework is very mighty and almost breaks the old one. In fact, this kind of reform movement, which was led by the government for the general public from top to bottom, was very common in China. The reason is the social background of China at that time: the highly centralized planned economy system. Whether the people's commune in the countryside or the system of Danwei in the city is a special form of organization that meets the needs of concentration. Only under the Chinese socialist system, production, resource allocation and product consumption can be regulated in all aspects by the government. Then the government had the superiority of the socialist concentrating power in major affairs to quickly broke through the original farmland framework, and efficiently led the general public to rebuild the city.

The second one is the durability of town plan, pattern of building forms, and pattern of urban land use. From the point of view of time attributes, M.R.G Conzen thinks that town plan has the strongest stability, pattern of building forms is the second, and pattern of urban land use is the most variable. The street is the most refractory element of the town plan. But in fact, he did not distinguish between the morphological importance of the same category. As a whole, the stability of the street structure is stronger than the building texture, but the streets also have grades. Low grade road stability may not be higher than high-grade buildings. But in view of the development process of Sanlitun, we can find a special presence - Embassy district. The pattern of maintaining its particularity and stability from beginning to end remains unchanged, and has not been disturbed by external changes.

\begin{tabular}{|c|c|c|c|c|c|}
\hline Morphological period & Spacial practice. & $\begin{array}{l}\text { Dynamic } \\
\text { mechanism }\end{array}$ & Nature & $\begin{array}{l}\text { Foreign } \\
\text { culture }\end{array}$ & $\begin{array}{l}\text { Socialist } \\
\text { system }\end{array}$ \\
\hline $\begin{array}{l}\text { Pre-modern agricutural } \\
\text { landscape period }\end{array}$ & $\begin{array}{l}\text { Primitive irrigation } \\
\text { canals and fields }\end{array}$ & $\begin{array}{l}\text { Government and } \\
\text { authorities }\end{array}$ & $\begin{array}{c}\text { Government and } \\
\text { social system } \\
\text { lead } \\
\text { development }\end{array}$ & 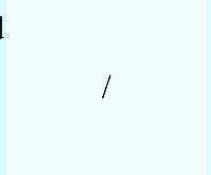 & \\
\hline $\begin{array}{l}\text { Socialism intial } \\
\text { accertion period }\end{array}$ & Danwei system & $\begin{array}{l}\text { Government leads } \\
\text { masses of society }\end{array}$ & Danwei system & $\begin{array}{l}\text { Embassy } \\
\text { district: the } \\
\text { source of } \\
\text { foreign culture }\end{array}$ & $\begin{array}{l}\text { Social system } \\
\text { restricts the } \\
\text { form and } \\
\text { determines } \\
\text { the different }\end{array}$ \\
\hline $\begin{array}{l}\text { Socialism } \\
\text { redevelopment period }\end{array}$ & $\begin{array}{c}\text { Community } \\
\text { system-New } \\
\text { commercial } \\
\text { housing estates, } \\
\text { commercial } \\
\text { facilities and public } \\
\text { service facilities }\end{array}$ & $\begin{array}{l}\text { Under the } \\
\text { supervision of the } \\
\text { government, masses } \\
\text { of society and the } \\
\text { capitalists compete } \\
\text { and cooperate with } \\
\text { each other }\end{array}$ & $\begin{array}{c}\text { Reform and } \\
\text { opening up } \\
\text { policy; Socialist } \\
\text { market } \\
\text { economic } \\
\text { system }\end{array}$ & $\begin{array}{l}\text { Bar Street: an } \\
\text { important } \\
\text { component of } \\
\text { consumer } \\
\text { space }\end{array}$ & $\begin{array}{c}\text { spatial } \\
\text { practice }\end{array}$ \\
\hline
\end{tabular}

Figure 10.

The Dynamic Nature of Spatial Practice in Sanlitun during Different Periods. 
The Embassy district is even more difficult to change than the streets. This indicates the strongest stability and mighty of town plan should be discussed under the distinction between region and importance.

Through this case study, we can find that M.R.G Conzen's theory is universal, but still needs us to reflect. For example, geographical features in Sanlitun had been removed thoroughly in a very short time. In contrast, the embassy district shows strong resistance to change, which makes us reflect on the degree of form persistence in systematic form complex. Also, during Danwei period. the method of dividing morphological units is still open to questions. Because of the integrity of Danwei system, the living, production and service unit should be considered as a unit of a whole. Therefore, in order to develop urban morphological theories, we should pay more attention to cross-cultural comparative study in urban morphology.

According to the above summary of content, what Sanlitun urban landscape reflects the most important particularity of urban form is the nature of revolutionary, which is the fundamental feature of socialism spatial practice of with Chinese characteristics. The nature of revolutionary specificly manifests that the succession of urban landscape can be completed quickly beyond the limitation of time and space, and has a distinctive institutional brand of the times. The evolution of revolutionary planning measures in Sanlitun is essentially due to differences in cultural institutions. Conzen once mentioned that the morphological theory was excluded from cities affected by revolutionary planning measures. After China and Sanlitun experienced revolutionary socialist transformation, they also found the practicality and particularity of Conzen 's theory. Therefore, in order to improve Conzen`s theory, we should pay more attention to the importance of cross-cultural comparative study in urban form.

\section{References}

Conzen, M.R.G. Alnwick, Northumberland: a study in town-plan analysis [M]. Publication
No. 27, Institute of British Geographers, London, 1960; reprinted with minor amendments and Glossary, 1969.

Conzen, M.R.G. The plan analysis of an English city centre[M]. Ohlssons Boktryckeri, 1962,. 11-1-:383-414.

Conzen, M.R.G. Historical townscapes in Britain: a problem in applied geography[J]. Northern geographical essays in honour of GHJ Daysh, 1966: 56-78.

Conzen, M.R.G. The use of town plan analysis in the study of urban history[J]. The study of urban history, 1968-5:68-77.

Conzen, M.R.G. Morphogenesis, morphological regions and secular human agency in the historic townscape, as exemplified by Ludlow[J]. Urban historical geography: recent progress in Britain and Germany, 1988: 253-72.

Conzen, M.R.G. Thinking about urban form: papers on urban morphology, 19321998[M]. Peter Lang, 2004.

Conzen, M.R.G. A Needed Re-Orientation in Urban Geography (Considering the Nature of Geography) [A]. Thinking about Urban Form[C], 1970, 24-33.

Conzen, M.R.G. The Morphology of Towns in Britain during the Industrial Era [J]. The Urban Landscape, 1978, 87-126.

Conzen, M.R.G. The Historical Urbanization Regions of Medieval Europe [A]. Thinking about Urban Form [C], 2004, 278-279.

Conzen, M.R.G. Morphogenesis and structure of the historic townscape in Britain[J]. Thinking about urban form: Papers on Urban Morphology, 1985: 1932-1998.

Conzen, M.P. How cities internalize their former urban fringes: a cross-cultural comparison[J]. Urban Morphology, 2009, 13(1): 29.

Conzen, M. P. From Alnwick to Cincinnati Teasdale property cycles in the old world and the new [J]. Urban Morphology, 2002, 6(1), 39-44.

Whitehand J.W.R. Conzenian urban morphology and urban landscapes[C]// Proceedings of the 6th International Space Syntax Symposium. 2007.

Whitehand, J.W.R. The changing face of cities: a study of development cycles and urban form[M]. Blackwell, 1987. 
Whitehand, J.W.R. Gu K. Conserving urban landscape heritage: A geographical approach $[\mathrm{J}]$. Procedia-Social and Behavioral Sciences, 2010, 2(5): 6948-6953.

Carl Ortwin Sauer. Historical Geography and the Western Frontier $[\mathrm{M}] / /$ John Leighly. Land and Life $[\mathrm{M}]$. Berkeley and Los Angeles: University of California Press, 1963: 32-41,45-52-104-117.

Cataldi G, Maffei G L, Vaccaro P. Saverio Muratori and the Italian school of planning typology[J]. Urban Morphology, 2002, 6(1): 3-14.

Schlüter O. Bemerkungen zur Siedelungsgeographie[J]. Geographische Zeitschrift, 1899, 5(2. H): 65-84.

Birkhamshaw A J, Whitehand JW R. Conzenian urban morphology and the character areas of planners and residents[J]. Urban Design International, 2012, 17(1): 4-17.

Moudon A V. Urban morphology as an emerging interdisciplinary field[J]. Urban morphology, 1997, 1(1): 3-10.

Castells M. The City and the Grassroots [M]. London: Edward Arnold.1983.

Castells M. Translated by Alan Sheridan. The Urban Question [M]. Cambridge Mass: The MIT Press (Original work published1972.1976). 1977.

Lefebvre H., Translated by D. Nicholson Smith. The Production of Space[M]. Oxford: Blackwell(Original work published 1974), 1991 $\square 33-39$.

Harvey D. Social Justice and the City [M]. London: Edward Arnold, 1973.

Smith N.O'Keefe P. Geography. Marx and the Concept of Nature[J]. Antipode. 1989. 12:30 39.

Gregory D. Geographical Imaginations [M]. Cambridge MA\&Oxford UK: Blackwell, 1994.

Chao Y E, Chai Y W, Zhang X L. REVIEW ON STUDIES ON PRODUCTION OF URBAN SPACE[J]. Economic Geography, 2011.

Andrew Wald. An economic sociological study on the working unit system in Chinese cities [J]. Foreign Sociology, 1991, 5: 26-32.

Harvey D. The urbanization of capital[M]. Oxford UK:Basil Blackwell Ltd1985.p.15, 1985. 